\title{
HUBUNGAN KEKUATAN OTOT LENGAN DAN KOORDINASI MATA TANGAN TERHADAP AKURASI SERVIS ATAS BOLA VOLI PADA PESERTA PUTRI EKSTRAKURIKULER DI SMAN 2 SELUMA
}

\author{
Dela Saptiani \\ Universitas Bengkulu E-mail: delasaptiani@gmail.com \\ Sugiyanto \\ Universitas Bengkulu \\ Syafrial \\ Universitas Bengkulu
}

\begin{abstract}
Abstrak
Penelitian ini bertujuan untuk mengetahui hubungan kekuatan otot lengan dan koordinasi mata tangan terhadap akurasi servis atas bola voli pada peserta ekstrakurikuler putri di SMAN 2 Seluma. Penelitian ini adalah penelitian korelasional dengan metode survei, Sampel penelitian menggunakan total sampling kemudian pengambilan data penelitian dengan teknik tes. Analisis statistik yang digunakan adalah uji lineritas, uji normalitas, uji hipotesis. Hasil penelitian Kekuatan otot lengan memiliki hubungan positif dengan kemampuan akuarsi servis bola voli dengan $t_{\text {hitung }}=2,34>t_{\text {tabel }}=2,093$ dan memberikan kontribusi sebesar $23 \%$, Koordinasi mata tangan memiliki hubungan positif dengan kemampuan akuarsi servis bola voli, dan Kekuatan otot lengan dan Koordinasi mata tangan secara bersama-sama memiliki hubungan positif dengan kemampuan akuarsi servis bola voli pada siswi ekstrakurikuler di SMAN 2 Seluma, dengan thitung $=3,38>t_{\text {tabel }}=2,093$ dan memberikan kontribusi sebesar $48 \%$. Dengan demikian maka dapat disimpulkan bahwa kekuatan otot lengan dan koordinasi mata tangan secara bersama-sama memiliki hubungan positif dengan akurasi servis atas bola voli.
\end{abstract}

Kata kunci: Kekuatan Otot Lengan, Koordinasi Mata Tangan, Servis Atas

\begin{abstract}
Abstrac
This study aims to determine the relationship of arm muscle strength and hand eye coordination to the accuracy of service on volleyball in female extracurricular participants at SMAN 2 Seluma. This study is a correlational study with survey methods. The research sample used total sampling and then took research data with test techniques. Statistical analysis used is linearity test, normality test, hypothesis test. Research results Arm muscle strength has a positive relationship with volleyball service acquisition ability with tcount $=2.34>t$ table $=2,093$ and contributes $23 \%$, hand eye coordination has a positive relationship with volleyball service acquaintance capabilities, and arm muscle strength and coordination hand eyes together have a positive relationship with the ability of volleyball service acquaintance on extracurricular students at SMAN 2 Seluma, with tcount $=3.38>t$ table $=2,093$ and contribute $48 \%$. Thus it can be concluded that arm muscle strength and hand eye coordination together have a positive relationship with the accuracy of service on volleyball.
\end{abstract}

Keywords: Arm Muscle Strength, Hand Eye Coordination, Upper Service 


\section{PENDAHULUAN}

Permainan bola voli diciptakan pada tahun 1895 oleh William G. Morgan dari Amerika Serikat. Pada mulanya permainan ini bernama Mintonette, mengingat dari permainan ini dimainkan dengan melambungkan bola (memukul-mukul bola) sebelum bola tersebut menyentuh lantai, maka pada tahun 1896 oleh H.T. Halsted mengusulkan nama permainan menjadi "Volley Ball". Permainan bola voli di Indonesia sudah dikenal sejak tahun 1928, dibawa oleh guru-guru Belanda yang mengajar di sekolahsekolah lanjutan. Sejak PON II di Jakarta pada tahun 1951, sampai sekarang bola voli termasuk salah satu cabang olahraga yang resmi dipertandingkan (Syafruddin, 2004).

Menurut Anthony (1978) dalam permainan bola voli ada beberapa teknik dasar yang harus dikuasai. Teknik-teknik dalam permainan agar dapat bermain dengan baik, yaitu servis atas, servis bawah, passing atas, dan passing bawah. Adapula teknik lanjutan yaitu, smash, blocking, dan jumping service. Saat melakukan teknik-teknik dengan benar menggunakan kemampuan koordinasi kekuatan dan akurasi.

Kemampuan servis atas didukung oleh koordinasi gerak seluruh tubuh yang berkahir dalam bentuk gerak ayunan didukung oleh kekuatan otot lengan sehingga menghasilkan akurasi yang baik. Koordinasi mata dan tangan yang baik, juga menguntungkan untuk dapat mengarahkan pukulan bola dengan arah bola yang diinginkannya. Dalam melakukan sebagai serangan bola pada daerah lawan yang kosong, lawan akan sulit menjangkau bola. Kemampuan seorang pemain bola voli untuk memadukan unsur koordinasi mata tangan dan kekuatan otot lengan saat melakukan teknik dasar akan berpengaruh terhadap baik buruknya akurasi yang dihasilkan.

Salah satu usaha untuk meningkatkan kemampuan siswa bidang olahraga di sekolah adalah dengan menambahkan waktu diluar jam pelajaran. Kegiatan yang dilakukan diluar jam pelajaran itu berupa kegiatan ekstrakurikuler. Kegiatan ekstrakurikuler merupakan aktivitas yang digunakan untuk dapat mengembangkan bakat, minat dan potensi yang mereka miliki sesuai dengan karakteristik masing-masing. Prestasi ekstrakurikuler SMAN 2 Seluma kurang baik, karena kurangnya variasi latihan untuk meningkatkan koordinasi kekuatan otot lengan dan akurasi servis atas pada pemain. Servis atas disebut juga awal dari serangan, di mana pemain harus memukul bola sekeras mungkin dan diarahkan pada posisi yang sulit di jangkauan lawan dengan koordinasi mata dan tangan. Pada ekstrakurikuler SMAN 2 Seluma jarang melakukan servis atas sebagai serangan saat bermain bola voli. Pada saat servis atas bola sering keluar lapangan, tidak melampaui net, tepat mengarah ke lawan dan mudah dikuasai sehingga menjadi kurang efektif. Tidak diketahuinya tingkat koordinasi, kuatnya otot lengan, dan akurasi pemain, sehingga peneliti ingin meneliti hubungan kekuatan otot lengan dan koordinasi mata tangan terhadap akurasi servis atas pada permainan ekstrakurikuler bola voli putri di SMAN 2 Seluma.

Kekuatan menurut pendapat Ismaryati (2009) adalah tenaga kontraksi otot yang dicapai dalam sekali usaha maksimal. Usaha maksimal ini dilakukan oleh otot atau sekelompok otot untuk mengatasi suatu tahanan. Kekuatan merupakan unsur yang sangat penting dalam suatu aktivitas olahraga, karena kekuatan merupakan daya penggerak, dan pencegah cedera. Selain itu kekuatan memainkan peranan penting dalam 
komponen-komponen kemampuan fisik yang lain misalnya power, kelincahan dan kecepatan dengan demikian kekuatan merupakan faktor utama untuk menciptakan prestasi yang optimal.

Menurut Ismaryati (2009), koordinasi didefinisikan sebagai hubungan yang harmonis dari hubungan saling pengaruh diantara kelompok-kelompok otot selama melakukan kerja, yang ditunjukan dengan berbagai tingkat ketrampilan. Sedangkan Menurut Ahmadi, (2007) mengemukakan bahwa, koordinasi adalah kemampuan seseorang dalam mengitegrasikan atau menghubungkan bermacam-macam gerakan yang berbeda kedalam bentuk gerakan tunggal secara efektif. Mengenai indikator koordinasi Sukadiyanto (2002) menyatakan bahwa indikator utama koordinasi adalah ketepatan dan gerak yang ekonomis.

Pada mulanya servis hanya merupakan pukulan pembukaan untuk memulainya suatu pertandingan, dengan berkembangnya permainan bola voli kini servis dijadikan serangan untuk mendapatkan poin sehingga kini servis sudah sangat berkembang teknik maupun variasi dari servis itu sendiri. Adapun teknik-teknik dalam permainan bola voli antara lain: (1) servis tangan bawah (underhand service), (2) servis mengapung (floating service; floating overhand serve, overhand change service) (overhand roundhouse service), (3) jumping service. METODE

Penelitian ini merupakan penelitian korelasional dengan metode survei. Data pada penelitian ini diambil dengan teknik tes, yang bertujuan untuk mengetahui hubungan antara variabel bebas dan variable terikat. maka dalam penelitian ini peneliti ingin mengetahui hubungan kekuatan otot lengan dan koordinasi mata tangan terhadap akurasi servis atas pada permainan ekstrakurikuler bola voli putri di SMAN 2 Seluma. Sebagai populasi dalam penelitian ini adalah peserta ekstrakurikuler voli di SMA Negeri 2 Seluma berjumlah 50 orang dengan sampel 20 Orang.

Menurut Arikunto (2002) Instrumen penelitian adalah alat bantu yang digunakan dan dipilih oleh peneliti dalam kegiatannya mengumpulkan data agar kegiatan tersebut menjadi sistematis dan dipermudah. Dalam penelitian ini digunakan instrumen tes sebagai alat untuk mengumpulkan data, tes yang digunakan yaitu:

Pengukuran terhadap kekuatan otot lengan dilakukan tes push-up (Fenanlampir dan Faruq, 2015:62). Alat yang digunakan yaitu, matras atau lantai yang datar dan rata

tes lempar tangkap bola tenis yang dipantulkan ke net. Satuan tes lempar tangkap bola ini adalah jumlah bola yang masuk dari 20 kali lemparan (Fenanlampir dan Faruq, 2015).

\section{HASIL PENELITIAN}

HASIL

Data variabel kekuatan otot lengan dikumpulkan melalui tes kekuatan otot lengan mengguakan push up kepada 20 orang testi. Dari hasil pengolahan data terlihat bahwa kekuatan otot lengan tertinggi yang dapat dicapai siswa adalah 21 dan terendah adalah 13, rata-rata nilai kekuatan otot lengan adalah 16,10 dengan standar deviasi 2,29.

Tabel 1.

Distribusi Frekuensi Kekuatan Otot Lengan ( $\left.\mathrm{X}_{1}\right)$

\begin{tabular}{|c|c|c|c}
\hline \multirow{2}{*}{ No } & Kekuatan & \multicolumn{2}{|c}{ Frekuensi } \\
\cline { 3 - 4 } & Otot Lengan & Absolut & Relative \\
\hline 1 & $21-22$ & 1 & $5 \%$ \\
\hline 2 & $19-20$ & 2 & $10 \%$ \\
\hline 3 & $17-18$ & 6 & $30 \%$ \\
\hline 4 & $15-16$ & 5 & $25 \%$ \\
\hline 5 & $13-14$ & 6 & $30 \%$ \\
\hline \multicolumn{2}{|c|}{ Jumlah } & $\mathbf{2 0}$ & $\mathbf{1 0 0 \%}$ \\
\hline
\end{tabular}




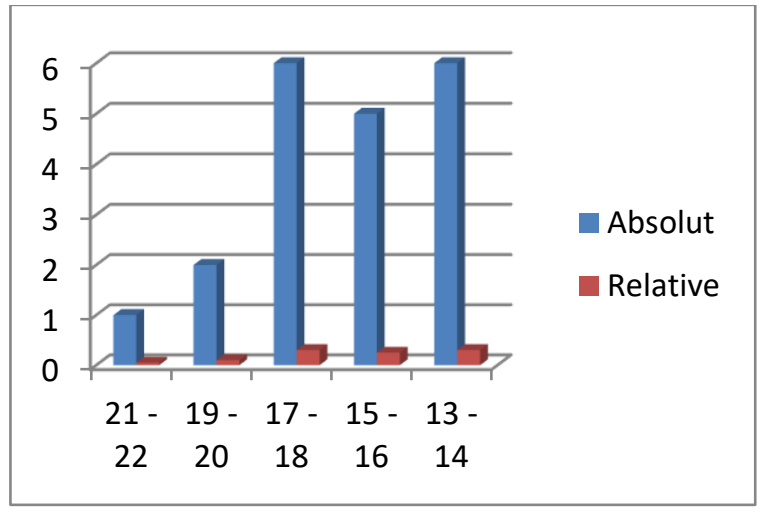

Gambar 1

Histogram Kekuatan Otot Lengan

Data variabel koordinasi mata tangan dikumpulkan melalui tes lempar tangkap bola voli kepada 20 orang testi. Dari hasil pengolahan data terlihat bahwa koordinasi mata tangan tertinggi yang dapat dicapai siswa adalah 17 dan terendah adalah 10 , rata-rata nilai koordinasi mata tangan adalah 14,05 dengan standar deviasi 2,282.

Tabel 2.

Distribusi Frekuensi Koordinasi Mata Tangan $\left(X_{2}\right)$

\begin{tabular}{|c|c|c|c|}
\hline \multirow{2}{*}{ No } & \multirow{2}{*}{$\begin{array}{c}\text { Koordinasi } \\
\text { Mata Tangan }\end{array}$} & \multicolumn{2}{|c|}{ Frekuensi } \\
\cline { 3 - 4 } & Absolut & Relative \\
\hline 1 & $17-18$ & 4 & $20 \%$ \\
\hline 2 & $15-16$ & 5 & $25 \%$ \\
\hline 3 & $13-14$ & 4 & $20 \%$ \\
\hline 4 & $11-12$ & 5 & $25 \%$ \\
\hline 5 & $9-10$ & 2 & $10 \%$ \\
\hline & Jumlah & $\mathbf{2 0}$ & $\mathbf{1 0 0 \%}$ \\
\hline
\end{tabular}

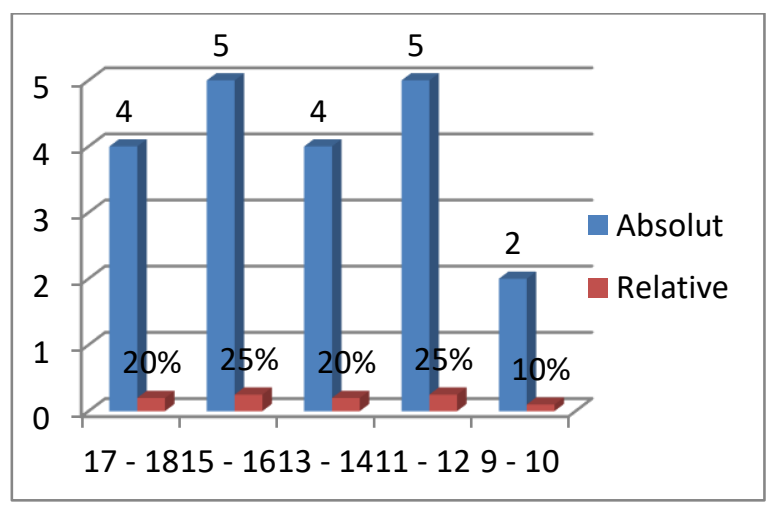

Gambar 2

Histogram Koordinasi Mata Tangan

Data variabel akurasi servis bola voli dikumpulkan melalui tes servis atas kepada 20 orang testi. Dari hasil pengolahan data terlihat bahwa akurasi servis bola voli tertinggi yang dapat dicapai siswa adalah 26 dan terendah adalah 12 , rata-rata nilai akurasi servis bola voli adalah 15,70 dengan standar deviasi 3,21.

\section{Tabel 3}

Distribusi Frekuensi Akurasi Servis Atas Bola Voli $\left(X_{3}\right)$

\begin{tabular}{|c|c|c|c|}
\hline \multirow{2}{*}{ No } & Akurasi & \multicolumn{2}{|c|}{ Frekuensi } \\
\cline { 3 - 4 } & Servis & Absolut & Relative \\
\hline 1 & $24-26$ & 1 & $5 \%$ \\
\hline 2 & $21-23$ & 0 & $0 \%$ \\
\hline 3 & $18-20$ & 3 & $15 \%$ \\
\hline 4 & $15-17$ & 10 & $50 \%$ \\
\hline 5 & $12-14$ & 6 & $30 \%$ \\
\hline \multicolumn{2}{|c|}{ Jumlah } & $\mathbf{2 0}$ & $\mathbf{1 0 0 \%}$ \\
\hline
\end{tabular}

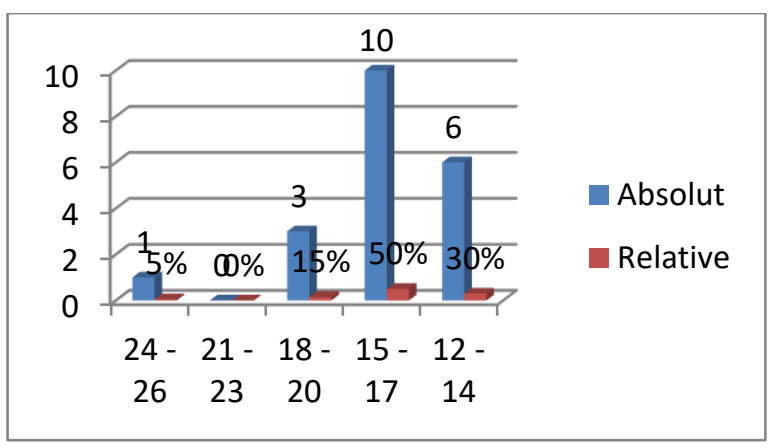

\section{Gambar 3}

\section{Histogram Akurasi Servis Atas Bola Voli}

Uji normalitas dilakukan terhadap variabel menggunakan uji Liliefors dengan taraf signifikansi $\alpha=0,05$, kriteria pengujian adalah bahwa $\mathrm{H}_{0}$ ditolak apabila $\mathrm{L}_{0}$ yang diperoleh dari data pengamatan melebihi $L_{t}$ dan sebaliknya $H_{0}$ diterima apabila $L_{t}$ lebih besar dari $L_{0}$. 
Hasil perhitungan lengkap uji normalitas dapat dilihat pada lampiran halaman. Dan sebagai rangkumannya terlihat pada tabel berikut:

Tabel 4 Rangkuman Hasil Uji Normalitas Data Penelitian

\begin{tabular}{||c|c|c|c|}
\hline Variabel & $\begin{array}{c}\mathbf{x}^{\mathbf{2}} \\
\text { hitung }\end{array}$ & $\begin{array}{c}\mathbf{x}^{\mathbf{2}} \text { tabel } \boldsymbol{\alpha} \\
\mathbf{= 0 , 0 5}\end{array}$ & Kesimpulan \\
\hline $\begin{array}{c}\text { Y atas } \\
\text { varians } X_{1}\end{array}$ & 31,41 & 1,96 & Homogen \\
\hline $\begin{array}{c}\text { Y atas } \\
\text { varians } X_{2}\end{array}$ & 31,41 & 1,98 & Homogen \\
\hline
\end{tabular}

\begin{tabular}{|c|c|c|c|c|}
\hline Variabel & $\mathbf{n}$ & $\mathbf{L}_{\mathbf{0}}$ & $\mathbf{L}_{\mathbf{t}}$ & Kesimpulan \\
\hline $\begin{array}{c}\text { Kekuatan } \\
\text { Otot Lengan } \\
\left(\mathrm{X}_{1}\right)\end{array}$ & 20 & 0,1344 & 0,1900 & Normal \\
\hline $\begin{array}{c}\text { Koordinasi } \\
\text { Mata Tangan } \\
\left(\mathrm{X}_{2}\right)\end{array}$ & 20 & 0,1655 & 0,1900 & Normal \\
\hline $\begin{array}{c}\text { Akurasi } \\
\text { Servis Atas (Y) }\end{array}$ & 20 & 0,1862 & 0,1900 & Normal \\
\hline
\end{tabular}

\section{Uji Linearitas}

Uji linearitas adalah uji yang dilakukan untuk melihat apakah masing-masing data variabel kekuatan otot lengan dan koordinasi mata tangan, cendrung membentuk garis linear terhadap variabel akurasi servis atas bola voli siswi ekstrakurikuler di SMAN 2 Seluma. $\mathrm{H}_{0}$ yang diuji dalam hal ini adalah data kekuatan otot lengan $\left(X_{1}\right)$ dan koordinasi mata tangan $\left(X_{2}\right)$, memiliki hubungan yang linear terhadap akurasi servis atas bola voli (Y) siswi ekstrakurikuler di SMAN 2 Seluma. Kriteria pengujian adalah $\mathrm{H}_{0}$ diterima apabila nilai $F_{\text {hitung }}$ yang diperoleh dari perhitungan < $F_{\text {tabel. }}$ Rangkuman uji linearitas dapat dilihat pada tabel, sedangkan analisis pengujiannya dapat dilihat pada Lampiran 7 halaman 89.

Uji homogenitas untuk menguji apakah data variabel akurasi servis atas bola voli berasal dari populasi yang homogen atas varians, kekuatan otot lengan, koordinasi mata tangan. $\mathrm{H}_{0}$ yang diuji dalam hal ini adalah data akurasi servis atas bola voli (Y) siswi ekstrakurikuler di SMAN 2 Seluma atas varians kekuatan otot lengan $\left(X_{1}\right)$ dan koordinasi mata tangan $\left(\mathrm{X}_{2}\right)$, berasal dari populasi yang homogen. Kriteria pengujian adalah $\mathrm{H}_{0}$ diterima apabila nilai $\mathrm{x}^{2}$ hitung yang diperoleh dari perhitungan $<x^{2}$ tabel. Rangkuman uji homogenitas dapat dilihat pada tabel, sedangkan analisis pengujiannya dapat dilihat pada Lampiran 5 halaman 88.

Tabel 5

Rangkuman Hasil Uji Homogenitas Variabel Akurasi Servis Atas Bola Voli (Y) atas varians Kekuatan Otot Lengan $\left(\mathrm{X}_{1}\right)$ dan Koordinasi Mata Tangan.

\section{Tabel 6}

Rangkuman Hasil Uji Linearitas Variabel Kekuatan Otot Lengan $\left(\mathrm{X}_{1}\right)$ dan Koordinasi Mata Tangan dengan Akurasi Servis Atas Bola Voli (Y).

\begin{tabular}{|c|c|c|c|}
\hline Variabel & $\mathbf{F}_{\text {hitung }}$ & $\begin{array}{c}\mathbf{F}_{\text {tabel }} \boldsymbol{\alpha}= \\
\mathbf{0 , 0 5}\end{array}$ & Kesimpulan \\
\hline $\mathrm{X}_{1}-\mathrm{Y}$ & 0,141 & 2,69 & Linear \\
\hline $\mathrm{X}_{2}-\mathrm{Y}$ & $-3,002$ & 2,69 & Linear \\
\hline
\end{tabular}

\section{Pembahasan}

\section{A. Pengujian Hipotesis}

Setelah uji persyaratan analisis dilakukan, ternyata semua skor tiap variabel penelitian memenuhi persyaratan untuk dilakukan pegujian statistik lebih lanjut. Maka selanjutnya dilaksanakan pengujian hipotesis penelitian, yakni: 1) kekuatan otot lengan memiliki hubungan positif dengan Akurasi 
servis bola voli, 2) koordinasi mata tangan memiliki hubungan positif dengan Akurasi servis bola voli, 3) kekuatan otot lengan, koordinasi mata tangan secara bersama-sama memiliki hubungan yang positif dengan Akurasi servis bola voli. Uji statistik yang digunakan adalah analisis korelasi pada taraf signifikansi $\alpha=0,05$. Untuk lebih jelasnya akan disajikan secara berurutan sebagai berikut.

1. Kekuatan Otot Lengan memiliki Hubungan Positif dengan Akuarsi Servis Bola Voli pada siswi ekstrakurikuler di SMAN 2 Seluma

Hasil analisis menunjukkan bahwa kekuatan otot lengan $\left(X_{1}\right)$ memiliki hubungan positif dengan akurasi servis bola voli siswi ekstrakurikuler di SMAN 2 Seluma. Nilai persamaan regresinya dapat digambarkan sebagai berikut $\hat{Y}=4,794+0,677 X$ terhadap Fhitung $(5,479)>F_{\text {tabel }}(4,41)$. Selanjutnya berdasarkan analisis linearitas regresi diperoleh nilai $F_{\text {hitung }}(0,141)<F_{\text {tabel }}(2,69)$. Hal ini menyatakan bahwa data berada dalam keadaan linear. Dengan demikian hipotesis yang diajukan $\left(\mathrm{H}_{\mathrm{a}}\right)$ dapat diterima. Untuk lebih jelasnya dapat dilihat pada tabel berikut:

Tabel 7.

Analisis Korelasi $X_{1}$ dengan $Y$

\begin{tabular}{|c|c|c|c|c|c|}
\hline $\begin{array}{c}\text { Korelasi } \\
\text { Antara }\end{array}$ & $\begin{array}{c}\text { Koefisien } \\
\text { Korelasi }\end{array}$ & $\begin{array}{c}\text { Koefisien } \\
\text { Determinasi }\end{array}$ & $\mathrm{t}_{\text {hitung }}$ & $\begin{array}{c}\mathrm{t}_{\text {tabel }} \\
\alpha= \\
0,05\end{array}$ & Kesimpulan \\
\hline $\begin{array}{c}\mathrm{X}_{1} \\
\text { terhadap } \\
\mathrm{Y}\end{array}$ & 0,483 & 0,243 & 2,34 & 2,093 & $\begin{array}{c}\text { Hubungan } \\
\text { Positif }\end{array}$ \\
\hline
\end{tabular}

Selanjutnya pada tabel analisis korelasi data penelitian diperoleh koefisien korelasi kekuatan terhadap akurasi servis $r_{\text {hitung }}(0,483)$ dengan $t_{\text {hitung }}=2,34>t_{\text {tabel }}=$ 2,093 menyatakan bahwa terdapat hubungan positif dengan variabel $\mathrm{Y}$.

2. Koordinasi Mata Tangan memiliki Hubungan Positif dengan Akuarsi Servis Bola
Voli pada siswi ekstrakurikuler di SMAN 2 Seluma.

Hasil analisis menunjukkan bahwa koordinasi mata tangan $\left(X_{2}\right)$ memiliki hubungan positif dengan akuarsi servis bola voli pada siswi ekstrakurikuler di SMAN 2 Seluma. Nilai persamaan regresinya dapat digambarkan sebagai berikut $\hat{Y}=\mathbf{3 , 4 4 6}+$ 0,872X terhadap Fhitung 11,203 > $F_{\text {tabel }} 4,41$. Selanjutnya berdasarkan analisis linearitas regresi diperoleh nilai $F_{\text {hitung }}-3,002<F_{\text {tabel }}$ 2,69 . Hal ini menyatakan bahwa data berada dalam keadaan linear. Dengan demikian hipotesis yang diajukan $\left(\mathrm{H}_{\mathrm{a}}\right)$ dapat diterima.

Selanjutnya pada tabel analisis korelasi data penelitian diperoleh koefisien korelasi koordinasi mata tangan dengan akurasi servis $r_{\text {hitung }}(0,691)$ terhadap $t_{\text {hitung }}=$ $3,35>t_{\text {tabel }}=2,093$ menyatakan bahwa terdapat hubungan positif dengan variabel $Y$ (lihat Lampiran 8 halaman 83).

Tabel 8.

\section{Analisis Korelasi $\mathbf{X}_{\mathbf{2}}$ dengan $\mathbf{Y}$}

\begin{tabular}{|c|c|c|c|c|c|}
\hline $\begin{array}{c}\text { Korelasi } \\
\text { Antara }\end{array}$ & $\begin{array}{c}\text { Koefisien } \\
\text { Korelasi }\end{array}$ & $\begin{array}{c}\text { Koefisien } \\
\text { Determinas } \\
\mathrm{i}\end{array}$ & $\begin{array}{c}\mathrm{t}_{\text {hitun }} \\
\mathrm{g}\end{array}$ & $\begin{array}{c}\mathrm{t}_{\text {tabel }} \\
\alpha= \\
0,05\end{array}$ & Kesimpulan \\
\hline $\begin{array}{c}\mathrm{X}_{2} \\
\text { terhada } \\
\mathrm{pY}\end{array}$ & 0,619 & 0,384 & 3,35 & $\begin{array}{c}2,09 \\
3\end{array}$ & $\begin{array}{c}\text { Hubungan } \\
\text { Positif }\end{array}$ \\
\hline
\end{tabular}

3. Kekuatan Otot Lengan dan Koordinasi Mata Tangan secara bersama-sama memiliki Hubungan Positif dengan Akuarsi Servis Bola Voli pada siswi ekstrakurikuler di SMAN 2 Seluma.

Hipotesis yang diajukan dan dirumuskan sebagai berikut: kekuatan otot lengan dan koordinasi mata tangan secara bersama-sama memiliki hubungan positif dengan akuarsi servis bola voli pada siswi ekstrakurikuler di SMAN 2 Seluma. Pengujian hipotesis ketiga ini dilakukan menggunakan analisis regresi ganda dan korelasi ganda. Berdasarkan hasil perhitungan menghasilakan 
nilai $a=20,48, b_{1}=0,0,671, b_{2}=0,428$, terhadap demikian persamaan regresi $Y$ atas $\mathrm{X}_{1}$ dan $\mathrm{X}_{2}$ adalah $\hat{Y}=20,48-0,671 \mathrm{X} 1-$ 0,4284 .

\section{Pembahasan}

\section{Hubungan Kekuatan Otot Lengan dengan Akurasi Servis}

Pada uji hipotesis pertama yaitu kekuatan otot lengan memiliki hubungan positif dengan akurasi servis secara signifikan. Untuk melihat hubungan murni $X_{1}$ dengan $Y$ dikontrol oleh $X_{2}$ dilakukan analisis korelasi parsial. Analisis korelasi parsial data penelitian diperoleh koefisien korelasi kekuatan otot lengan dengan akuarsi servis dikontrol oleh koordinasi mata tangan $r_{\text {hitung }}$ $(0,483)$ dengan $t_{\text {hitung }}=2,34>t_{\text {tabel }}=2,093$ menyatakan bahwa terdapat hubungan positif antara $X_{1}$ dengan $Y$ apabila dikontrol oleh $X_{2}$. Artinya bahwa variabel kekuatan otot lengan sebagai independent variabel memiliki hubungan positif sebesar $23 \%$ dengan dependent variabel yakni akuarsi servis bola voli pada siswi ekstrakurikuler di SMAN 2 Seluma.

Dari penjelasan diatas dapat diartikan bahwa kekuatan otot lengan memiliki hubungan yang positif dengan kemampuan akurasi servis.

\section{Hubungan Koordinasi Mata Tangan dengan Akurasi Servis}

Pada uji hipotesis kedua yaitu koordinasi mata tangan memiliki hubungan positif dengan kemampuan akurasi servis secara signifikan. Untuk melihat hubungan murni $X_{2}$ dengan $Y$ dikontrol oleh $X_{1}$ dilakukan analisis korelasi parsial. Analisis korelasi parsial data penelitian diperoleh koefisien korelasi koordinasi mata tangan dengan akurasi servis dikontrol oleh kekuatan otot lengan $r_{\text {hitung }}(0,619)$ terhadap thitung $3,35>$ $t_{\text {tabel }}$ 2,093 menyatakan bahwa terdapat hubungan positif antara $\mathrm{X}_{2}$ dengan $\mathrm{Y}$ apabila dikontrol oleh $X_{1}$. Artinya bahwa variabel koordinasi mata tangan sebagai independent variabel memiliki hubungan positif sebesar $38 \%$ terhadap dependent variabel yakni akuarsi servis bola voli pada siswi ekstrakurikuler di SMAN 2 Seluma.

Untuk mengetahui hubungan antar variabel dimana skor pada suatu variabel dapat digunakan untuk memprediksi skor pada variabel lainnya dilakukan analisis regresi linear sederhana. Dari hasil analisis diperoleh persamaan regresi $\hat{Y}=3,446+$ 0,872X. Model persamaan regresi ini mengandung arti bahwa apabila koordinasi mata tangan ditingkatkan pada satu skor, maka kecendrungan kemampuan akuarasi servis atas bola voli meningkat sebesar 0,384 pada konstanta 4,7126.

Dari penjelasan diatas dapat diartikan bahwa koordinasi mata tangan memiliki hubungan yang positif dengan kemampuan akuarsi servis. Menurut bompa (2000) koordinasi mata-tangan akan menghasilkan timing dan akurasi. Timing berorientasi pada ketetapan waktu sedangkan akurasi berorientasi pada ketepatan sasaran. Melalui timing yang baik maka perkenaan antara tangan dan objek akan sesuai dengan keinginan, sehingga menghasilkan gerakan yang efektif. Akuarsi akan menentukan tepat dan tidaknya objek kepada sasaran yang dituju. Oleh sebab itu, koordinasi matatangan sangat pentingdalam melakukan passing agar bisa tepat pada sasaran yang diinginkan. Artinya dengan memiliki koordinasi mata tangan yang tinggi memiliki hubungan yang positif dengan kemampuan akurasi servis atas bola voli.

2. Hubungan Kekuatan Otot Lengan dan Koordinasi Mata Tangan Secara Bersamasama dengan Kemampuan Akurasi Servis. 
Pada uji hipotesis ketiga yaitu kekuatan otot lengan dan koordinasi mata tangan secara bersama-sama memiliki hubungan positif dengan kemampuan akuarsi servis secara signifikan. Hal ini dibuktikan oleh koefisien korelasi yang ditemukan sebesar 0,6964 . Berdasarkan uji keberartian korelasi antara pasangan skor Kekuatan otot lengan $\left(X_{1}\right)$ dan koordinasi mata tangan $\left(X_{2}\right)$ dengan akurasi servis atas bola voli $(\mathrm{Y})$, diperoleh Fhitung $(4,121)>F_{\text {tabel }}(2,88)$ pada taraf signifikansi $\alpha=0.05$. Berdasarkan hasil pengujian di atas, maka dapat disimpulkan Kekuatan otot lengan dan Koordinasi mata tangan secara bersama-sama memiliki hubungan positif dengan akurasi servis atas bola voli.

Untuk mengetahui hubungan antar variabel dimana skor pada suatu variabel dapat digunakan untuk memprediksi skor pada variabel lainnya dilakukan analisis regresi linear sederhana. Dari hasil analisis diperoleh persamaan regresi $\hat{Y}=20,48$ 0,671 X1 - 0,4284. Model persamaan regresi ini mengandung arti bahwa apabila kekuatan otot lengan dan koordinasi mata tangan ditingkatkan pada satu skor, maka kecendrungan akurasi servis atas bola voli sebesar 0,671 X1 dan 0,4284 pada konstanta $-2,11$.

Dari penjelasan diatas dapat diartikan bahwa kekuatan otot lengan dan koordinasi mata tangan secara bersama-sama memiliki hubungan yang positif dengan kemampuan akuarsi servis. Semakin meningkat kekuatan otot lengan dan koordinasi mata tangan maka akan semakin meningkat kemampuan akurasi servis seorang siswi. Begitu pula sebaliknya Semakin rendah kekuatan otot lengan dan koordinasi mata tangan maka akan semakin rendah kemampuan akurasi servis seorang siswi.
Kekuatan otot lengan dan koordinasi mata tangan sangat diperlukan untuk melakukan servis sehingga memberikan hubungan positif secara signifikan terhadap kemampuan akurasi servis siswi. Hal ini berarti bahwa siswi yang memiliki tingkat Kekuatan otot lengan dan koordinasi mata tangan yang baik akan memudahkan untuk melakukan gerakan servis, sehingga atlet mampu memposisikan bola dengan benar tepat pada sasaran.

\section{KESIMPULAN}

Berdasarkan hasil penelitian dan pembahasan, maka didapat kesimpulan sebagai berikut :

1. Kekuatan otot lengan memiliki hubungan positif dengan kemampuan akuarsi servis bola voli pada siswi ekstrakurikuler di SMAN 2 Seluma, dengan $t_{\text {hitung }}=2,34>$ $t_{\text {tabel }}=2,093$ dan memberikan kontribusi sebesar $23 \%$.

2. Koordinasi mata tangan memiliki hubungan positif dengan kemampuan akuarsi servis bola voli pada siswi ekstrakurikuler di SMAN 2 Seluma, dengan $t_{\text {hitung }}=3,35>t_{\text {tabel }}=2,093$ dan memberikan kontribusi sebesar 38\%.

3. Kekuatan otot lengan dan Koordinasi mata tangan secara bersama-sama memiliki hubungan positif dengan kemampuan akuarsi servis bola voli pada siswi ekstrakurikuler di SMAN 2 Seluma, dengan $t_{\text {hitung }}=3,38>t_{\text {tabel }}=2,093$ dan memberikan kontribusi sebesar $48 \%$.

\section{DAFTAR PUSTAKA}

Ahmadi, Nuril. 2007. Suatu Gerakan Dalam Permainan Bolavoli. Jakarta: Universitas terbuka. 
Arikunto, Suharsimi. 2006. Prosedur Undang-Undang Dasar Republik Indonesia Penelitian Suatu Pendekatan Praktik. $\quad$ Nomor 2. 1989. Sistem Pendidikan Jakarta: Rineka Cipta.

Arsil. 2010. Penelitian Tes Koordinasi Mata

Tangan. Jakarta: Universitas Terbuka.

Barlian, Eri. 2016. Metodologi Penelitian Kualitatif \& Kuantitatif. Padang: Sukabina Press.

Beutelstahl, Dieter. 2001. Pengertian Servis Dalam Permainan Bolavoli. Jakarta: Universitas terbuka.

Bompa, Tudor O. 2000. Kooordinasi Mata Tangan. Jakarta: Universitas terbuka.

Depdikbud. 1994. Undang-Undang RI. Jakarta: Departemen Pendidikan dan Kebudayaan.

Edwan, Ari, dan Bogy. 2017. "Pengaruh Metode Latihan Plyometric Terhadap Kemampuan Jumping Smash Bola Voli Siswa Ekstrakurikuler SMPN 1 Bermani Ilir Kabupaten Kepahiang" Jurnal Kinestetik, Vol. 1 (1).

Fenanlampir, Albertus dan Muhammad Muhyi Faruq. 2015. Tes \& Pengukuran dalam Olahraga. Yogyakarta: CVANDI OFFSET.

Ismaryati. 2009. Tes Dan Pengukuran Olahraga. Surakarta: UNS Press.

Mukholid, Agus. 2010. Pengertian Passing Dalam Permainan Bolavoli. Jakarta: Universitas terbuka.

Syarifuddin, Aip. 1997. Sejarah dan Teknik Permainan Bola Voli. Jakarta: Rineka Cipta. 